\title{
Britannica
}

In Verbindung mit dem Seminar für englische Sprache und Kultur an der Hamburgischen Universität herausgegeben von

\section{Emil Wolff}

\author{
Heft 1
}





\title{
Die englische Biographik der Tudor-Zeit
}

\author{
Von \\ Dr. Marie Schütt
}

Friederichsen, de Gruyter \& Co. m. b. H. / Hamburg 1930 
Druck von J. J. Augustin in Glâckstadt und Hambarg. 


\section{Prof. Emil Wolff}

$$
\text { zu eigen }
$$


